\title{
Estudo dos fatores de virulência associados à formação de biofilme e agrupamento filogenético em Escherichia coli isoladas de pacientes com cistite
}

\author{
Study on virulence factors associated with biofilm formation and phylogenetic \\ groupings in Escherichia coli strains isolated from patients with cystitis
}

\author{
Monique Ribeiro Tibaํ, Gustavo Prado Nogueira' ${ }^{1}$ e Domingos da Silva Leite ${ }^{1}$
}

\begin{abstract}
RESUMO
Amostras de Escherichia coli, isoladas de pacientes do sexo feminino com quadro clínico de cistite, foram caracterizadas quanto à presença de fatores de virulência associados à formação de biofilme e ao agrupamento filogenético. Os resultados da reação em cadeia da polimerase demonstraram que todas as amostras foram positivas para o gene fimH (fímbria do tipo1), 91 amostras foram positivas para o gene fliC (flagelina) 50 amostras positivas para o gene $p a p C$ (fímbria P), 44 amostras positivas para o gene kpsMTII (cápsula) e 36 amostras positivas para 0 gene $f l u$ (antígeno 43). Os resultados dos ensaios de quantificação da formação de biofilme demonstraram que 44 amostras formaram biofilme em microplacas de poliestireno e 56 amostras apresentaram resultado ausente/fraco. Também confirmamos a incidência das amostras de Escherichia coli no grupo filogenético B2 e D.
\end{abstract}

Palavras-chaves: Escherichia coli uropatogênica. Reação em cadeia da polimerase. Biofilme bacteriano.

\section{ABSTRACT}

Escherichia coli samples isolated from female patients with cystitis were characterized with regard to the presence of virulence factors associated with biofilm formation and phylogenetic groupings. Polymerase chain reaction results demonstrated that all the samples were positive for the gene fimH (type 1 fimbriae), 91 for fliC (flagellins), 50 for papC (P fimbriae), 44 for kpsMTII (capsules) and 36 for flu (antigen 43). The results from assays to quantify the biofilm formation demonstrated that 44 samples produced biofilm on polystyrene microplates and 56 samples produced weak or no biofilm. We also confirmed that Escherichia coli samples were present in phylogenetic groups B2 and D.

Key- words: Uropathogenic Escherichia coli. Polymerase chain reaction. Bacterial biofilm.

Escherichia coli uropatogênica (UPEC) é o principal agente que ocasiona infecções no trato urinário (ITU), além de ser uma das fontes mais comuns de bacteremia em indivíduos hospitalizados ${ }^{17}$. Este agente é responsável por $80 \%$ das ITUs, sendo que, $95 \%$ de todas estas infecções, desenvolvem-se em uma rota ascendente ${ }^{12}$.

Dentre os principais fatores de virulência, presentes no estabelecimento da infecção no trato urinário, estão as adesinas (fímbria do tipo 1, fímbria P, fímbria $S$, adesinas Afa/Dr), que promovem a colonização e formação de biofilme $e^{15}$.

\footnotetext{
1. Laboratório de Antígenos Bacterianos II, Departamento de Microbiologia e Imunologia, Instituto de Biologia, Universidade Estadual de Campinas, Campinas. SP. Apoio financeiro: Fundação de Amparo a Pesquisa do Estado de São Paulo - FAPESP (Processo 05/02473-4) e Coordenação de Aperfeiçoamento de Pessoal de Nível Superior - CAPES.

Endereço para correspondência: Dr. Domingos da Silva Leite. Laboratório de Antígenos Bacterianos II, Depto de Microbiologia e Imunologia, IB/UNICAMP. Cidade Universitária Zeferino Vaz, 13081-970 Campinas, SP.

Tel: 55 193521-6272.

e-mail: domingos@unicamp.br

Recebido em:5/09/2008

Aceito em 09/12/2008
}

Escherichia coli uropatogênica também tem sido encontrada formando biofilme bacteriano, que confere importantes vantagens aos microrganismos como resistência à desidratação e oxidação e maior tolerância a detergentes e antibióticos ${ }^{26}$.

Diversas linhagens de Escherichia coli patogênica ou comensais são capazes de colonizar superfícies pela expressão de estruturas de adesão como flagelo, pili conjugativo, polissacarídeos extracelulares e curli, formando o biofilme bacteriano ${ }^{2}$.

Foi descrito o papel da adesina antígeno 43 (Ag43), atuando na persistência da UPEC no trato urinário ${ }^{21}$. A expressão do Ag 43, codificada pelo gene $f l u$, resulta em auto-agregação das células, promovendo a formação de biofilme bacteriano e a sobrevivência e persistência da bactéria durante uma infecção prolongada ${ }^{9}$.

A expressão da fímbria do tipo 1 tem sido reportada por ser esta uma importante estrutura para formação do biofilme, devido sua adesão celular inicial ${ }^{23}$. Enquanto a adesão mediada pela fímbria do tipo 1 é importante durante os estágios iniciais de colonização, a motilidade e quimiotaxia do flagelo bacteriano permitem que a UPEC se dissemine para novos sítios do trato urinário, tanto para obter nutrientes quando estes se tornam limitados, quanto para escapar da resposta imune do hospedeiro $^{10}$. Como as infecções do trato urinário ocorrem de 
maneira ascendente, tem-se sugerido que a motilidade mediada pelo flagelo contribua para a virulência das bactérias, uma vez que permite a disseminação bacteriana no trato urinário ${ }^{10}$.

Os polissacarídeos capsulares são produzidos por muitas UPEC e estão associados à proteção contra a fagocitose, além de contribuírem para a formação de biofilme na bexiga ${ }^{14}$. Porém, estudos demonstram que a expressão da cápsula é reduzida na formação do biofilme, por mascarar outras estruturas de superfície $^{18}$. Estudos epidemiológicos moleculares demonstraram que amostras de Escherichia coli podem ser divididas em quatro grupos filogenéticos designados A, B1, B2 e D³. Amostras que causam infecções extra-intestinais, como ITU, meningite e septicemia, têm sido classificadas no grupo B2, ou, menos frequentemente, no grupo $\mathrm{D}^{24}$. Amostras dos grupos B2 e D são conhecidas por possuírem mais fatores de virulência do que as amostras pertencentes aos grupos A e $\mathrm{B} 1^{16}$.

0 objetivo deste trabalho foi caracterizar genotipicamente 100 amostras de Escherichia coli uropatogênicas, quanto aos fatores de virulência associados à formação de biofilme, bem como demonstrar em ensaios fenotípicos a formação de biofilme e motilidade. Além disso, foi realizado o estudo do agrupamento filogenético das cepas de Escherichia coli uropatogênicas.

\section{MATERIAL E MÉTODOS}

Amostras bacterianas. Foram utilizadas 100 amostras de Escherichia coli, coletadas na década de 1990, e isoladas de pacientes do sexo feminino, atendidas nos ambulatórios do Hospital das Clínicas da Universidade de Campinas (UNICAMP), Campinas, São Paulo, apresentando quadro clínico de cistite. Foram excluídas as pacientes, que no momento da coleta, apresentassem febre, e/ou mal estado geral que pudesse caracterizar suspeita clínica de pielonefrite aguda ou qualquer quadro infeccioso. Pacientes com anomalias do trato urinário, ou qualquer doença de base também foram excluídos. 0 diagnóstico de cistite foi baseado pelos sintomas clínicos típicos como ardor à micção, polaquiúria, urgência urinária e/ou perda urinária de esforço e urocultura com contagem de colônias superior a $10^{5} \mathrm{UFC} / \mathrm{ml}$, com crescimento de um único tipo de microrganismo.
Estas amostras são pertencentes à Bacterioteca do Laboratório de Antígenos Bacterianos II, Departamento de Microbiologia e Imunologia, Instituto de Biologia, UNICAMP, Campinas, São Paulo.

Obtenção de DNA para reação em cadeia da polimerase. As amostras foram cultivadas em caldo de infusão de cérebro e coração (BHI) a $37^{\circ} \mathrm{C}$ por 24 horas. Após este procedimento, foram repicadas em ágar TSA (ágar tripticase de soja) a $37^{\circ} \mathrm{C}$ por $24 \mathrm{~h}$ para obtenção de crescimento confluente. Em seguida, um raspado de cada uma das amostras foi ressuspendido em $100 \mu \mathrm{L}$ de água deionizada estéril. A suspensão bacteriana obtida foi fervida por 10 minutos e centrifugada a 10.000 rpm por 2 minutos. Os sobrenadantes assim obtidos foram utilizados para a reação em cadeia da polimerase (PCR).

Reação em cadeia da polimerase. A reação em cadeia da polimerase foi realizada utilizando-se iniciadores específicos para os genes: $p a p C$ (proteína de membrana externa da fímbria P), fimH (adesina da fímbria do tipo1), kpsMTII (cápsula), fliC (flagelo), flu (antígeno 43), chuA, yja, tspE (grupos filogenéticos). A sequiência dos iniciadores, temperatura de anelamento e peso molecular dos produtos estão especificados na Tabela 1.

Os produtos da PCR foram aplicados em gel de agarose 1,5\%-2\%, sendo identificados mediante incubação em solução de brometo de etídio e visualizados em transiluminador de luz UV. Para registro, os géis foram fotografados no sistema ImageMaster VDS (Amersham Pharmacia Biotech Inc. EUA).

Quantificação da formação de biofilme. A formação de biofilme foi realizada através da utilização de microplacas de poliestireno com 96 orifícios de fundo chato (Costar $®, 3596)^{20}$. As amostras foram classificadas de acordo com a produção de biofilmes em quatro grupos: não produtoras, fracas, moderadas ou fortes.

Teste de motilidade. As cepas de Escherichia coli foram semeadas em uma das extremidades de tubos U contendo meio de cultura semi-sólido MIL (Himedia) e incubados por 24 horas a $37^{\circ} \mathrm{C}$.

\section{TABELA 1}

Iniciadores utilizados na reação em cadeia de polimerase, tamanho molecular do produto amplificado, temperatura de anelamento e referência bibliográfica.

\begin{tabular}{|c|c|c|c|c|}
\hline Gene & Sequiência de oligonucleotídios $\left(5^{\prime} \rightarrow 3^{\prime}\right)$ & Produto amplificado (pb) & $\mathrm{TA}\left({ }^{\circ} \mathrm{C}\right)$ & Referência \\
\hline$p a p C$ & 1:GAC GGC TGT ACT GCA GGG TGT GGC G2: ATA TCC TTT CTG CAG GGA TGC AAT A & 328 & 63 & 4 \\
\hline $\mathrm{fimH}$ & 1: TGC AGA ACG GAT AAG CCG TGG2 GCA GTC ACC TGC CCT CCG GTA & 508 & 63 & 7 \\
\hline kpsMTII & 1: GCG CAT TTG CTG ATA CTG TTG2: CAT CAG ACG ATA AGC ATG AGC A & 272 & 63 & 7 \\
\hline flic & 1:ATG GCA CAA GTC ATT AAT ACC CAA C2:CTA ACC CTG CAG CAG AGA CA & variável & 60 & 5 \\
\hline$f l u$ & 1: TCACGATAACAATGGCGGTA2: AGTCCCCACACGCATATCTC & 670 & 60 & 3 \\
\hline $\operatorname{chuA}$ & 1: GACGAACCAACGGTCAGGAT2: TGCCGCCAGTACCAAAGACA & 279 & 55 & 3 \\
\hline yja & 1: TGAAGTGTCAGGAGACGCTG2: ATGGAGAATGCGTTCCTCAAC & 211 & 55 & 3 \\
\hline tspE4.C2 & 1: GAGTAATGTCGGGGCATTCA2: CGCGCCAACAAAGTATTACG & 152 & 55 & 3 \\
\hline
\end{tabular}

TA: temperatura de anelamento $\mathrm{em}^{\circ} \mathrm{C}, p a p C$ : proteína de membrana externa da fímbria $\mathrm{P}$, fimH: adesina fímbrial do tipo1, $k p s M T I I$ : montagem do grupo II capsular-K e $\mathrm{K} 5$, fliC: flagelina, flu: antígeno 43, chuA: transporte do grupo heme da hemoglobina, yjaA: função desconhecida e tspE4.C2: fragmento anônimo de DNA.

G: guanina, A: adenina, C: citocina, T: timina. 


\section{RESULTADOS}

Um total de 100 amostras de Escherichia coli uropatogênicas foram genotipicamente caracterizadas através do método da PCR. Os resultados da PCR demonstraram que todas as amostras (100\%) foram positivas para o gene fimH, 91 (91\%) amostras foram positivas para o gene $f l i C, 50(50 \%)$ amostras positivas para o gene $p a p C, 44$ (44\%) amostras positivas para o gene kpsMTII e $36(36 \%)$ amostras positivas para o gene $f u$.

Considerando que dentre as 100 amostras analisadas, 50\% também possuíam o gene para a fímbria $\mathrm{P}$, as amostras foram divididas em dois grupos para análise dos resultados. No Grupo1, foram reunidas as amostras positivas para os genes $p a p C$ e no Grupo 2 as negativas para o mesmo gene $p a p C$. Os resultados da PCR estão presentes na Tabela 2.

0 gene $f l u$ foi encontrado em 27 amostras do grupo 1, e em nove amostras do grupo 2 (Tabela 2). Já no teste fenotípico, 29 amostras do grupo 1 formaram biofilme moderado ou forte e no grupo 2 foram encontradas 15 amostras formando biofilme moderado ou forte. 0 gene kpsMTII foi amplificado apenas no grupo 1, sendo detectadas 44 amostras positivas (Tabela 2).

0 gene flic foi amplificado em 46 amostras do grupo 1 e em 45 amostras do grupo 2 (Tabela 2). Das 46 amostras fliC, 29 expressaram motilidade em meio de cultura semi-sólido. No grupo 2, das 45 amostras positivas para o gene fliC, 42 amostras expressaram motilidade (Tabelas 3 e 4).

Os resultados dos ensaios de quantificação da formação de biofilme demonstraram que das 100 amostras de Escherichia coli estudadas, 44 amostras formaram biofilme em microplacas de poliestireno e 56 amostras apresentaram resultado ausente/ fraco.

Neste trabalho, o gene flic foi detectado em 47 amostras que formaram biofilme ausente/fraco, e em todas as amostras de biofilme moderado (36 amostras) e forte (8 amostras). Porém, a motilidade em meio semi-sólido foi observada em 37 amostras que apresentaram biofilme ausente/fraco, em 26 amostras que tinham biofilme moderado e em todas as oito amostras que formaram biofilme forte.

Foi observado que das 56 amostras que apresentaram resultado ausente/fraco, apenas oito amostras eram positivas para o gene $f l u$. Das 36 amostras de biofilme moderado, 20 amostras tinham o gene flu e todas as oito amostras de biofilme forte eram positivas para o gene $f l u$.

0 estudo do agrupamento filogenético identificou que do total de 100 amostras estudadas, 34 (34\%) amostras foram classificadas no grupo filogenético A, 4 (4\%) amostras no grupo B1, 48 (48\%) amostras no grupo B2 e 14 (14\%) amostras no grupo D (Tabelas 3 e 4).

\section{TABELA 2}

Distribuição dos fatores de virulência e do agrupamento filogenético de Escherichia coli isoladas de pacientes apresentando quadro clínico de cistite.

\begin{tabular}{|c|c|c|c|c|c|c|c|c|c|c|c|c|c|c|c|c|}
\hline \multirow[b]{2}{*}{ FV } & \multicolumn{8}{|c|}{$\begin{array}{c}\text { Grupo } 1 \\
\text { amostras } p a p C \text { positivas }\end{array}$} & \multicolumn{8}{|c|}{$\begin{array}{c}\text { Grupo } 2 \\
\text { amostras } p a p C \text { negativas }\end{array}$} \\
\hline & $f h u$ & $\mathrm{fimH}$ & $k p s$ & flic & $\mathrm{A}$ & $\mathrm{B} 1$ & $\mathrm{~B} 2$ & $\mathrm{D}$ & $f l u$ & $\mathrm{fimH}$ & $k p s$ & flic & $\mathrm{A}$ & B1 & $\mathrm{B} 2$ & $\mathrm{D}$ \\
\hline$f l u$ & 27 & 27 & 24 & 24 & 1 & - & 21 & 5 & 9 & 50 & - & 8 & 4 & - & 4 & 1 \\
\hline $\mathrm{fimH}$ & 27 & 50 & 44 & 46 & 2 & 1 & 40 & 7 & 9 & 50 & - & 45 & 32 & 3 & 8 & 7 \\
\hline$k p s$ & 24 & 44 & 44 & 40 & 2 & 1 & 36 & 5 & - & - & - & - & - & - & - & - \\
\hline$f l i c$ & 24 & 46 & 40 & 46 & 2 & - & 38 & 6 & 8 & 50 & - & 45 & 29 & 3 & 7 & 6 \\
\hline Total $n^{0}=100$ & 27 & 50 & 44 & 46 & 2 & 1 & 40 & 7 & 9 & 50 & 0 & 45 & 32 & 3 & 8 & 7 \\
\hline
\end{tabular}

PapC: proteína de membrana externa da fimbria P, FV: fatores de virulência, flu: antígeno 43, fimH: fímbria do tipo1, $k p s$ : cápsula, fliC: flagelina, A: grupo filogenético A, B1: grupo filogenético B1, B2: grupo filogenético B2, D grupo filogenético D.

TABELA 3

Distribuição das amostras de Escherichia coli positivas para o gene $p a p C$ com relação à intensidade do biofilme formado e os fatores de virulência.

\begin{tabular}{lrrrrrrrrrr}
\hline & \multicolumn{10}{c}{ Grupo1 (amostras $p a p C$ positivas) } \\
\cline { 2 - 12 } & $f l u$ & $f i m H$ & $k p s$ & $p a p C$ & $f l i C$ & Mil & A & B1 & B2 & D \\
\hline Fraco/ausente & 5 & 21 & 19 & 21 & 17 & 10 & 1 & 1 & 16 & 3 \\
Moderado & 16 & 23 & 19 & 23 & 23 & 13 & - & - & 20 & 3 \\
Forte & 6 & 6 & 6 & 6 & 6 & 6 & 1 & - & 4 & 1 \\
\hline Total $\mathrm{n}^{\circ}=50$ & 27 & 50 & 44 & 50 & 46 & 29 & 2 & 1 & 40 & 7
\end{tabular}

papC: proteína de membrana externa da fímbria $\mathrm{P}, \mathrm{FV}$ : fatores de virulência, flu: antígeno 43, fimH: fímbria do tipo1, kps: cápsula, fliC: flagelina, Mil: Meio Motilidade Indol Lisina, A: grupo filogenético A, B1: grupo filogenético B1, B2: grupo filogenético B2, D: grupo filogenético D.

\section{TABELA 4}

Distribuição das amostras de Escherichia coli negativas para o gene $p a p C$ com relação à intensidade do biofilme formado e os fatores de virulência.

\begin{tabular}{lrrrrrrrrrr}
\hline & \multicolumn{8}{c}{ Grupo 2 (amostras $p a p C$ negativas) } \\
\cline { 2 - 11 } FV & $f l u$ & $f i m H$ & $k p s$ & $p a p C$ & $f l i C$ & Mil & A & B1 & B2 & D \\
\hline Fraco/ausente & 3 & 35 & - & - & 30 & 27 & 26 & 2 & 2 & 5 \\
Moderado & 4 & 13 & - & - & 13 & 13 & 5 & 1 & 5 & 2 \\
Forte & 2 & 2 & - & - & 2 & 2 & 1 & - & 1 & - \\
\hline Total $\mathrm{n}^{0}=50$ & 9 & 50 & - & - & 45 & 42 & 32 & 3 & 8 & 7 \\
\hline
\end{tabular}

papC: proteína de membrana externa da fímbria $\mathrm{P}, \mathrm{FV}$ : fatores de virulência, flu: antígeno 43, fimH: fímbria do tipo1, kps: cápsula, fliC: flagelina, Mil: Meio Motilidade Indol Lisina, A: grupo filogenético A, B1: grupo filogenético B1, B2: grupo filogenético B2, D: grupo filogenético D. 


\section{DISCUSSÃo}

Os ensaios da PCR permitiram a caracterização molecular dos fatores de virulência associados à formação de biofilme e o agrupamento filogenético das 100 amostras de Escherichia coli estudadas. Foram realizados testes fenotípicos de quantificação de formação de biofilme em microplacas de poliestireno e testes de motilidade em tubos contendo meio de cultura semi-sólido para avaliar a formação de biofilme e motilidade.

Aproximadamente, $50 \%$ das infecções microbianas são associadas com formações de biofilme, que aumentam significantemente a resistência à antibióticos e aos mecanismos de defesa do sistema imune. Estudos têm demonstrado a importância da formação de biofilme bacteriano em ITUs, principalmente em cistite crônica e infecções associadas ao uso de cateteres ${ }^{6}$, uma vez que, a presença do biofilme atua na diminuição da susceptibilidade das bactérias aos agentes antimicrobianos quando comparados com culturas de crescimento em suspensã $0^{19}$. 0 crescimento do biofilme está associado ao aumento da resistência aos agentes antimicrobianos e à susceptibilidade a estes agentes são mil vezes maiores nas culturas que crescem em suspensão (planctônicas) ${ }^{6}{ }^{19}$. Estudos sugerem que a resistência do biofilme é explicada pela impenetrabilidade dos agentes antimicrobianos devido à presença de um polímero hidrofílico que reveste o biofilme e a estratégias de liberação dos agentes antimicrobianos ${ }^{19}$

Das adesinas afimbriais (antígeno 43), a família da proteína AT (autotransportadora) representa um novo grupo de fatores de virulência que estão envolvidas na adesão, invasão e formação do biofilme ${ }^{21}$. Estudos sugerem que o fenômeno de agregação mediado pelo ag43 poderia ser bloqueado pela expressão concomitante da fimbria do tipo 1 , pois o contato célula-célula requerido pela adesina AT pode ser fisicamente bloqueado pela expressão de grandes estruturas extracelulares como fimbrias, flagelos, lipopolissacarídeo e cápsula ${ }^{921}$. Porém, neste trabalho, tanto o gene flu quanto a formação do biofilme em microplacas de poliestireno, foram detectados em maior prevalência nas amostras do grupo 1 que possuem tanto o gene para fímbria do tipo 1 quanto para fimbria $\mathrm{P}$, e também a presença do polissacarídeo capsular, do que nas amostras do grupo 2 que apresentaram apenas 1 operon fimbrial estudado e ausência do antígeno capsular (Tabela 2).

0 gene kpsMTII foi amplificado em 44 amostras do grupo 1, sendo que não foi encontrado em nenhuma amostra do grupo 2 (Tabela 1). Um estudo demonstrou que a cápsula pode bloquear a atividade de outras adesinas localizadas na superfície bacteriana, sugerindo que em bactérias onde não há expressão da cápsula há um aumento na formação do biofilme devido à expressão do antígeno $43^{14}$. Além disso, a função da fímbria do tipo 1 tem sido reportada por impedir a presença da cápsula na superfície bacteriana, e a síntese reduzida deste polissacarídeo pode aumentar a contribuição da fímbria para a formação do biofilme ${ }^{14}$. Neste trabalho, observamos que nas 50 amostras do grupo 2 positivas para a fímbria do tipo 1, nenhuma delas apresentavam o gene kpsMTII, demonstrando que nas 15 amostras que formaram biofilme em microplaca não houve participação da cápsula.
A motilidade tem papel essencial na formação do biofilme, provavelmente devido à superação da força de repulsão eletrostática das superfícies celulares, e por estar envolvida na colonização inicial da superfície celular do hospedeiro ${ }^{22} 23$. Foi demonstrado, que as diferenças na arquitetura da formação do biofilme, são causadas pela rotação flagelar ou pela presença da estrutura flagelar ${ }^{23}$ e que o flagelo é dispensável para formação de biofilme em amostras de Escherichia coli que expressam curli e em amostras que carregam o plasmídio conjugativo $\mathrm{F}^{22}$.

Das 46 amostras positivas para o gene fliC no grupo 1, 29 expressaram motilidade em meio de cultura semi-sólido. No grupo 2, das 45 amostras positivas para o gene fliC, 42 amostras expressaram motilidade (Tabelas 2 e 3). Estes resultados podem indicar que nas amostras do grupo 2, houve maior expressão de motilidade, pois encontram-se ausentes estruturas como cápsula ou adesinas.

0 estudo do agrupamento filogenético identificou que do total de 100 amostras estudadas, 34 (34\%) amostras foram classificadas no grupo filogenético A, 4 (4\%) amostras no grupo B1, 48 (48\%) amostras no grupo B2 e 14 (14\%) amostras no grupo D (Tabelas 2 e 3). A prevalência do grupo filogenético B2 nas amostras $p a p C$ positivas foi significativamente mais alto do que nas amostras $p a p C$ negativas (Tabela 3 e 4). Estes resultados eram esperados uma vez que, amostras agrupadas nos grupos B2 e D, são conhecidas por possuir mais fatores de virulência e estão associadas a infecções extra-intestinais ${ }^{81317}$.

Neste trabalho, observamos que o antígeno 43, responsável pela formação do biofilme, estava presente nas amostras que apresentaram formação de biofilme moderado e forte, além de poder estar associado a outros fatores de virulência na formação do biofilme em infecções urinárias, visto que houve maior prevalência deste gene no grupo de amostras que tinham a adesina $P$ e $o$ antígeno capsular. 0 gene fliC responsável pela motilidade foi encontrado em ambos os grupos, porém houve prevalência de expressão nas amostras do grupo 2. Estes dados sugerem que o flagelo pode estar associado a formação do biofilme na ausência de outras estruturas como as adesinas e a cápsula. Também confirmamos a incidência das amostras do grupo 1, no grupo filogenético B2 e D, uma vez que estas amostras possuem tanto a fímbria do tipo 1, quanto a fímbria $\mathrm{P}$, característica de infecções extra-intestinais.

\section{AGRADECIMENTOS}

Os autores agradecem o apoio financeiro da Fundação de Amparo a Pesquisa do Estado de São Paulo (FAPESP) e da Coordenação de Aperfeiçoamento de Pessoal de Nível Superior (CAPES) pela bolsa concedida a Monique Ribeiro Tiba.

\section{REFERÊNCIAS}

1. Barnich N, Boudeau J, Claret L, Darfeuille-Michaud A. Regulatory and functional co-operation of flagella and type 1 pili in adhesive and invasive abilities of AIEC strain LF82 isolated from a patient with Crohn's disease. Molecular Microbiology 48: 781-794, 2003. 
2. Castonguay MH, Van Der Schaaf S, Koester W, Krooneman J, Van Der Meer W, Harmsen H, Landini P. Biofilm formation by Escherichia coli is stimulated by synergistic interactions and co-adhesion mechanisms with adherence-proficient bacteria. Research in Microbiology 157: 471-478, 2006.

3. Clermont 0 , Bonacorsi S, Bingen E. Rapid and simple determination of the Escherichia coli phylogenetic group. Applied and Environmental Microbiology 66: 4555-4558, 2000.

4. Daigle F, Harel J, Fairbrother JM, Lebel P. Expression and detection of $p a p, s f a$, and $a f a$ - encoded fimbrial adhesin systems among uropathogenic Escherichia coli. Canadian Journal of Microbiology 40: 286-291, 1994.

5. Fields, PI, Blom K, Hughes HJ, Helsel LO, Feng P, Swaminathan B. Molecular characterization of the gene encoding $\mathrm{H}$ antigen in Escherichia coli and development of a PCR-restriction fragment length polymorphism test for identification of Escherichia coli 0157:H7 and 0157:NM. Journal of Clinical Microbiology 35: 1066-1070, 1997.

6. Hancock H, Ferriéres L, Klemm P. Biofilm formation by asymptomatic and virulent urinary tract infectious Escherichia coli strains. Federation of European Microbiological Societies - FEMS Microbiology Letters 267: 30-37, 2007.

7. Johnson JR, Stell AL. Extended virulence genotypes of Escherichia coli strains from patients with urosepsis in relation to phylogeny and host compromise. Journal of infection disease 181: 261-272, 2000

8. Kanamaru S, Kurazono H, Nakano M, Terai A, Ogawa O, Yamamoto S. Subtyping of uropathogenic Escherichia coli according to the pathogenicity island encoding uropathogenic-specific protein: Comparison with phylogenetic groups. International Journal of Urology 13: 754-760, 2006.

9. Kjaergaard K, Schembri MA, Ramos C, Molin S, Klemm P. Antigen 43 facilitates formation of multispecies biofilms. Environmental Microbiology 2: 695-702, 2000.

10. Lane MC, Alteri CJ, Smith SN, Mobley HLT. Expression of flagella is coincident with uropathogenic Escherichia coli ascension to the upper urinary tract. Proceedings of the National Academy of Sciences of the United States of America 104: 16669-16674, 2007.

11. Lane MC, Simms AN, Mobley HL. Complex interplay between type 1 fimbrial expression and flagellum-mediated motility of Uropathogenic Escherichia coli. Journal of Bacteriology 189: 5523-5533, 2007.

12. Mulvey MA. Adhesion and entry of uropathogenic Escherichia coli. Cellular Microbiology 4: 257-271, 2002
13. Nowrouzian FL, Adlerberth I, Wold AE. Enhanced persistence in the colonic microbiota of Escherichia coli strains belonging to phylogenetic group B2: role of virulence factors and adherence to colonic cells. Microbes and Infection 8: 834-840, 2006

14. Oelschlaeger TA, Dobrindt U, Hacker J. Virulence factors of uropathogens. Current Opinion Urology 12:33-38, 2002.

15. Ong CLY, Ulett GC, Mabbett AN, Beatson AS, Webb RI, Monaghan W, Nimmo GR, Looke DF, McEwan AG, Schembri MA. Identification of type 3 fimbriae in Uropathogenic Escherichia coli reveals a role in biofilm formation. Journal of Bacteriology 190: 1054-1063, 2008.

16. Picard B, Garcia JS, Gouriou S, Duriez P, Brahimi N, Bingen E, Elion J, Denamur E. The link between phylogeny and virulence in Escherichia coli extraintestinal infection. Infection and Immunity 67:546-53, 1999.

17. Pires MCS, Frota KS, Martins Junior PO, Correia AF, Cortez-Escalante JJ, Silveira CA. Prevalência e suscetibilidades bacterianas das infecções comunitárias do trato urinário, em Hospital Universitário de Brasilia, no período de 2001 a 2005. Revista da Sociedade Brasileira de Medicina Tropical 40: 643-647, 2007.

18. Schembri MA, Dalsgaard D, Klemm, P. Capsule shields the function of short bacterial adhesins. Journal of bacteriology 186: 1249-1257, 2004.

19. Smith AW. Biofilms and antibiotic therapy: Is there a role for combating bacterial resistance by the use of novel drug delivery systems? Advanced Drug Delivery Reviews 57: 1539-1550, 2005.

20. Stepanovi S, Cirkovi I, Ranin L, Svabi -Vlahovi M. Biofilm formation by Salmonella spp and Listeria monocytogenes on plastic surface. Letters in Applied Microbiolology 38:428-432, 2004

21. Ulett GC, Mabbett AN, Fung KC, Webb RI, Schembri MA. The role of F9 fimbriae of uropathogenic Escherichia coli in biofilm formation. Microbiology 157: 2321-2331, 2007.

22. Van Houdt R, Michiels CW. Role of bacterial cell surface stuctures in Escherichia coli biofilm formation. Research in Microbiology 156: 626-633, 2005.

23. Wood TK, Barrios AFG, Herzberg M, Lee J. Motility influences biofilm architecture in Escherichia coli. Applied Microbiology and Biotechnology 72: 361-367, 2006

24. Yamamoto S. Molecular epidemiology of uropathogenic Escherichia coli. Journal of Infection and Chemotherapy 13: 68-73, 2007. 